\title{
Euskokantauriar arroko eboluzio geologikoa II: konpresioaren eraginpean
}

\author{
Arturo Apraiz* \\ Geodinamika saila. Zientzia eta Teknologia Fakultatea (UPV/EHU) \\ Arantza Aranburu, Miren Mendia \\ Mineralogia eta Petrologia saila. Zientzia eta Teknologia Fakultatea (UPV/EHU) \\ Arantxa Bodego \\ Meatze eta Metalurgia Ingenieritza eta Materialen Zientzia saila \\ Meatzen eta Herri Lanen I.T.U.E. (UPV/EHU) \\ *arturo.apraiz@ehu.eus
}

DOI: $10.1387 /$ ekaia.14374

Jasoa: 2015-04-27

Onartua: 2015-10-07

Laburpena: Euskokantauriar arroaren eboluzioak oso iraupen luzea du. Konpresioa nagusi izan zen bitartean sortutako egiturek argi erakusten dute izaera desberdineko bi deformazio-fase suertatu direla. Lehenengoan, iparralderanzko bergentzia duten egiturak garatu ziren, eta, batez ere, Euskokantauriar arroaren iparraldeko arroan gorde dira. Bigarrenean, hegoalderanzko bergentzia duten egiturak dira nagusi, eta hauek, batez ere, Euskokantauriar arroaren hegoaldeko mugan garatu dira. Gaur egun, egitura hauen sorrera azaltzen duen ereduak Europako plaka Iberiako plakan ziri baten antzera sartu zela erakusten du.

Hitz-gakoak: Euskokantauriar arroa, konpresioa, egitura geologikoak, orogenia alpetarra

Abstract: The Basque Cantabrian basin has a very long evolutionary process. Structures generated while the compression was dominant clearly show that two stages of deformation were developed. The structures generated during the first deformationphase are north vergent, and they are essentially preserved in the northern part of the Basque-Cantabrian basin. During the second deformation-phase south vergent structures are dominant, and they are very well developed in the southern boundary of the Basque-Cantabrian basin. Currently, the tectonic model that explains the origin of these structures suggests that the European plate penetrates like a wedge in the Iberian plate.

Keywords: Basque Cantabrian basin, compression, geological structure, Alps orogeny. 


\section{KONPRESIOAREN ERAGINPEKO FASE TEKTONIKOAK}

Iberiar plakaren eta Europar plakaren konbergentziaren hasierak guztiz aldatu zituen aurreko eskema geologikoa eta ingurune sedimentarioak. Estentsioaren eraginpean hainbat milioi urtean hedatu zen arroa konpresioaren eragina pairatzen hasten da, Indiako ozeanoaren irekieraren ondorioz Afrikako plaka iparralderantz higitzen hasten delako Santoniar-Campaniarrean (75-85Ma). Hala ere, Euskokantauriar arroan sedimentazio itsastarrak ez du etenik izango; are gehiago, areagotu egingo da bi kontinenteen arteko kolisioaren hasiera ekialdean gertatzen delako, apurka-apurka mendebalderantz hedatzeko. Prozesu honetan sortutako erliebeak higadura bortitza jasango du eta Euskokantauriar arrora iristen den metakinen kopurua izugarri handituko da.

Pirinioak alpetar katearen jarraipena dira, Iberiar plakaren (S-an) eta Euroasiar plakaren (N-an) arteko konbergentzia-prozesuak sortua (1. irudia). Pirinioari buruzko bibliografia ugari dago, ikerketa geofisikoetan, petrolio-zundaketetan eta erdialdeko eta hego-isurialdeko Pirinioko azaleramendu apartetan oinarritua. Informazio horri esker, konbergentzia nolakoa izan den zehaztu ahal izan da. Hala ere, sismika sakoneko lehenengo profiletatik gaur egungo azken berrikuspenetaraino, garrantzi handiagoa eman zaio informazio geofisikoari landa-datuei baino. Horren ondorioz, desadostasunak sortu dira lurrazaleko egituraren eredu geofisikoen eta azaleramenduetatik ondorioztutako geodinamikaren artean. Nolanahi ere, landa-behaketek eta sakoneko datuek mendikatearen historia geologikoa islatzen dute; modu egokian interpretatzea besterik ez da falta [1].

Pirinioetako mendikateak forma simetrikoa du, eta gutxi gorabehera E-W norabidea (1. irudia). Hertziniar basamentua eremu axialean (erdialdean) azaleratzen da, eta estalki meso-zenozoikoa N-rantz eta S-rantz zamalkatzen da. Ipar Pirinioko zonako estalki sedimentarioa Akitaniako arroaren gainetik zamalkatzen da, eta Hego Pirinioko zona Ebroren eta Dueroren arro zenozoikoen gainetik. Ekialdeko eta erdialdeko Pirinioan, Iberia-Eurasia plaken muga Ipar Pirinioko failan kokatuta dagoela interpretatzen da (1. irudia); muga horrek mendebaldeko Pirinioan duen luzapena, Iruñeko failatik mendebaldera, Leitzako failari dagokio [2].

Iruñeko faila NE-SW orientazioko «nafar diapiroen lerrokadurak» definitzen du, eta transferentzia-faila bat da. Bi zona bereizten ditu: E-an, Pirinioak sensu stricto, eta W-an, Euskokantauriar arroa. Iruñeko failaren alde banatan diferentzia estratigrafiko handiak badira ere, alde bateko eta besteko egiturek jarraipena dute. Eremu Axialaren jarraipena Bortzirietako mazizo paleozoikoan dago. Ipar Pirinioko failak Leitzako failan eta Kalamuako hausturan du jarraipena. Ipar Pirinioko zonak Euskal Arkuan du baliokidea, eta Ipar Pirinioko fronteak Capbretongo itsaspeko arroilan. Hego Pirinioko zonak Euskokantauriar arroaren hegoaldean du jarraipena, eta 
Hego Pirinioko fronteak Toloño-Obarenes zamalkaduran. Beraz, zein bere aldetik tratatu ohi badira ere, Pirinioak eta Euskokantauriar arroak eboluzio bateratua izan dute, eta ezin da konpresioaren eraginpean Euskokantauriar arroak izan duen eboluzioa ulertu Pirinioaren eboluzioa ezagutu gabe. Euskokantauriar arroa, beraz, Pirinio mendikatearen \%35 inguru dela esan daiteke (1. irudia).

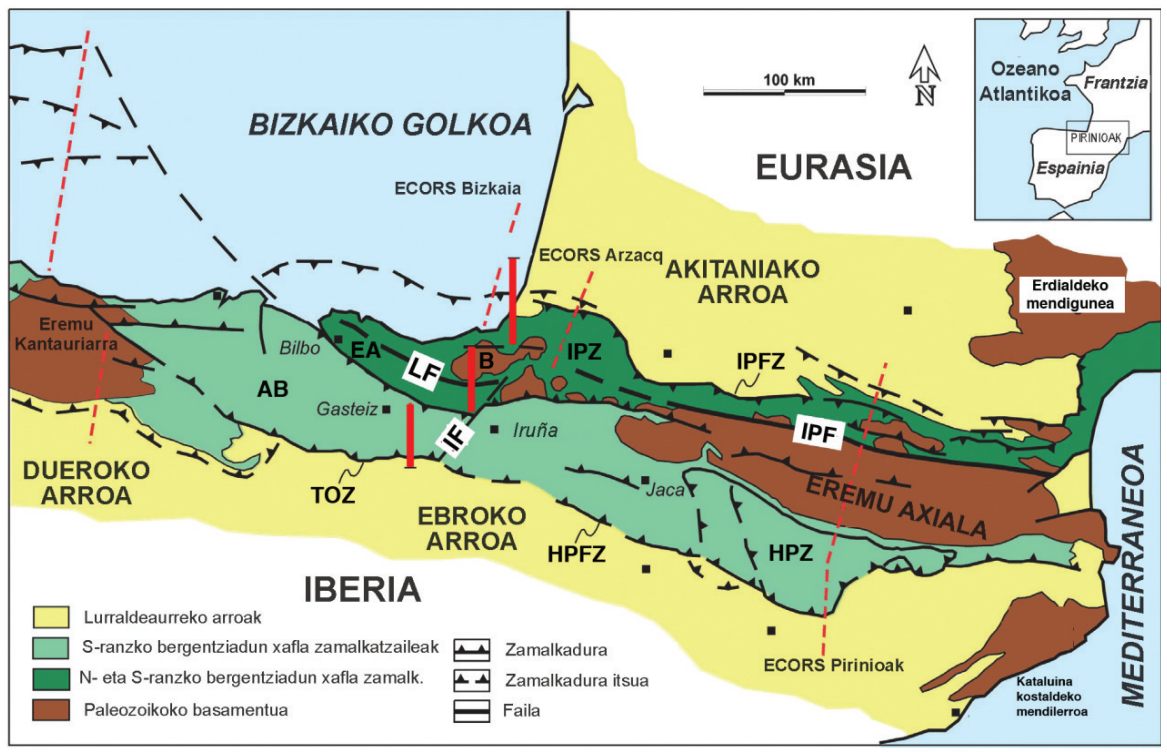

1. irudia. Pirinioetako mapa tektonikoa, testuan aipatutako unitate eta egiturak adierazten dituena. Erdialdeko Pirinioan: Ipar Pirinioko fronte-zamalkadura (IPFZ), Ipar Pirinioko zona (IPZ), Ipar Pirinioko faila (IPF), Hego Pirinioko zona (HPZ) eta Hego Pirinioko fronte-zamalkadura (HPFZ). Euskokantauriar arroan, Iruñeko failatik (IF) W-ra: Bortziriak (B), Euskal Arkua (EA), Leitzako faila (LF), Arabako Blokea (AB) eta Toloño-Obarenes zamalkadura (TOZ). Lerro etenak sakoneko sismikako profilen kokapenei dagozkie eta 2. irudiko zehar-ebakia lerro bertikal lodietan zehar burutu da ([1]-etik moldatua).

Euskokantauriar arroaren eboluzio geodinamikoa Iruñeko failatik mendebaldera kokatutako - Akitaniako arrotik Ebroko arrorainoko - zeharebaki geologiko batetik (2. irudia) abiatuta deskribatuko da lan honetan [1]. Zehar-ebaki horretan, hiru sekzio hartu dira kontuan (1. irudia). Sekziorik iparraldekoena Ipar Pirinioko zonaren mendebaldeko muturretik Bortzirietako mendigune axialeraino doa. Erdiko sekzioak Bortzirietako mendigune axialaren (iparraldean) eta Bilboko failaren arteko (hegoaldean) tartea hartzen du. Sekziorik hegoaldekoena, Bilboko failatik Ebroren arroraino luzatzen da. 
Estalkiaren zehar-ebaki geologikoaren azpian (2. irudia), basamentuaren egitura marraztu da falka bakuneko geometriarekin [3]. Kalkulatutako laburtzea estalkiari baino ez dagokio; basamentuaren azalerak ia konstante irauten du, Eurasia azpian subduzitutako Iberiar plakaren bolumena ezezaguna baita.

2. irudiko leheneratzean, bi fase bereizi dira. Lehena, talka-etapa zenozoikoaren barnean, iparralderanzko bergentziako lehen fase zenozoikoari dagokio. Bigarrena, hegoalderanzko bergentzia duen fase zenozoikoa da, eta gaur egungo profilari dagokio. Irudi berean, fase bakoitzari elkartutako gertaera tektoniko nagusiak adierazten dira. Ondoren, konpresioarekin lotutako bi fase nagusietan garatutako egituren ezaugarriak aztertuko dira.

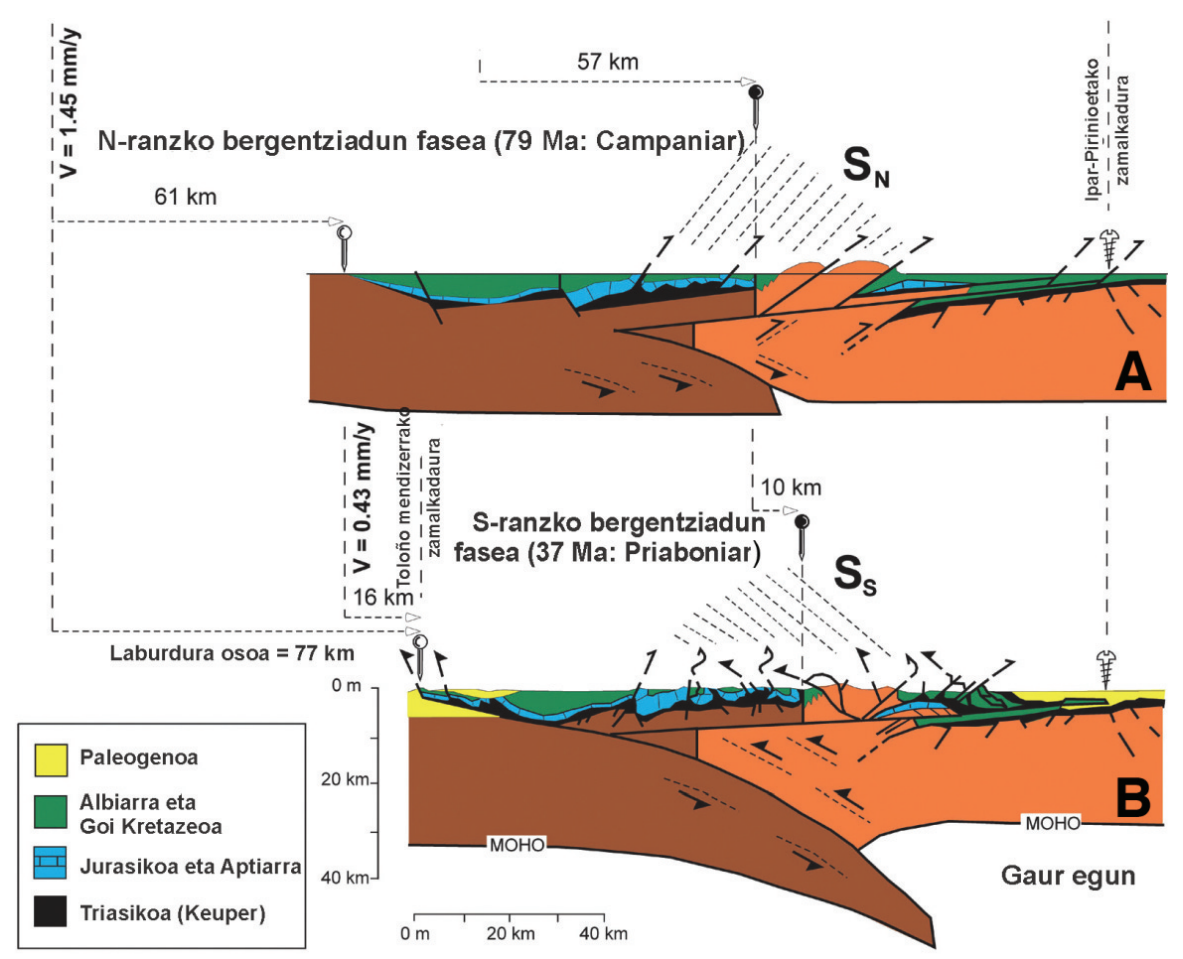

2. irudia. Euskokantauriar arroaren eboluzio kortikala. A: Campaniarrean Nranzko bergentziadun egiturak sortzen dira; B: Priaboniarrean S-ranzko bergentziadun egiturak. Zehar-ebakia 1. irudian kokatuta dago, Martínez-Torres (1993) lanaren arabera ([1]-etikmoldatua). 


\subsection{Iberia-Eurasia talka}

Goi-Kretazeoaren bukaeran, Afrikaren eta Eurasiaren arteko hurbilpenak Iberiaren eta Eurasiaren arteko talka zeiharra eragin zuen. Horren ondorioz sortutako egitura kortikala ondo ezagutzen da sakoneko sismikaren zenbait profili, askotariko prospekzio geofisikoei eta katearen zeharkako zehar-ebaki geologiko xehe batzuei esker. Pirinioen erdialdean burututako sakoneko sismikako ECORS-Pirinioak profilean (1. irudia) [4] argi ikusten da Iberiako plaka Eurasiako plakaren azpian subduzitzen dela, eta, prozesu horretan, plaka horren gaineko parte bat delaminatzen dela, prisma bat eratzeko. Prisma horrek gorakada bat jasaten du, Ipar eta Hego Pirinioko fronte-zamalkaduren bitartez (3. irudia). Gorputz delaminatuan modu aktiboan hartzen du parte basamentuak; basamentu horrek, gaur egun, Pirinioko Zona Axiala osatzen du. Sekzio horretarako kalkulatutako gutxieneko laburtzea $147 \mathrm{~km}$ da [5].

Euskokantauriar arrotik W-ra, Kantabriako eremuko profil sismikoetan, egitura kortikala falka tektoniko bakun hasiberri bati dagokio; Pirinioaren erdialdean deduzitutakoaren antzekoa da, baina laburtzea $50-55 \mathrm{~km}$ baino handiagoa ez dela izan dirudi [6].

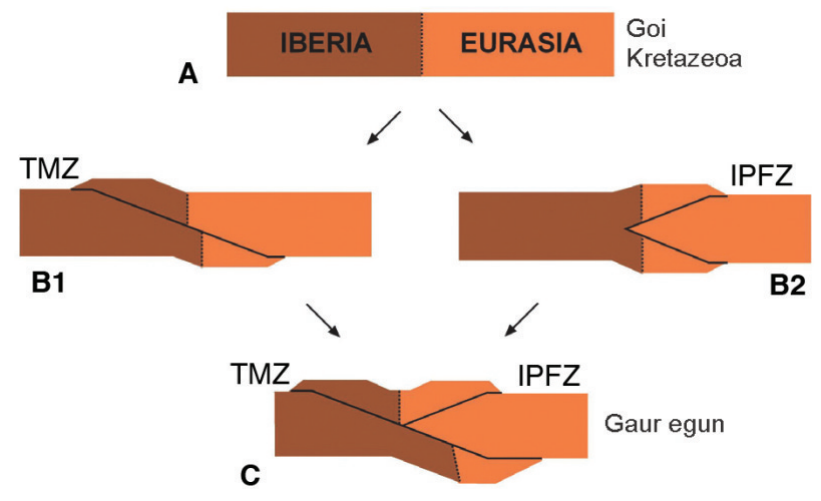

3. irudia. (A) Hasierako egoera konpresioaren aurretik. (C) Bukaerako egoera, atzerako zamalkadura elkartu bat -IPFZ (Ipar Pirinioko fronte-zamalkadura) duen zamalkadura nagusi - TMZ (Toloño mendilerroaren zamalkadura) - baten eskema. (B) Azkeneko geometria sortzeko bi bide daude: (B1) biderik arruntenean lehenik TMZ eta gero IPFZ garatuko ziren; (B2) Piriniotarako iradokitzen den ereduan, aldiz, falka tektoniko bategatik, lehenengo, IPFZ, eta gero, TMZa sortzen dira ([1]-etik moldatua).

Horrenbestez, Iberiaren eta Eurasiaren arteko talka-prozesuan falka tektoniko gisako egitura kortikal bat garatu zen, E-tik W-ra gutxituz doan laburtzea duena: 147 km-ko laburtze maximotik, Pirinioaren erdialdean, 
50-55 km-ra, Kantabriako eremuan. Euskokantauriar arroan, deskribatutako zehar-ebakiaren bitarteko kokapenagatik (1. irudia), onargarria izan daiteke jotzea egitura kortikala falka-formakoa dela eta bitarteko laburtzebalioak dituela.

Gaur egungo egitura litosferikotik abiatuta (3C. irudia), deduzitu zatekeen eredurik sinpleenean Hego Pirinioko fronteak zamalkadura nagusi gisa jokatuko luke eta haren gainean garatuko litzateke Ipar Pirinioko faila, atzerako zamalkadura gisa. Hala ere, landako datuek adierazten dute Hego Pirinioko zamalkadura Ipar Piriniokoaren ondorengoa dela, Ipar Pirinioko zamalkadurarekin batera garatutako N-ranzko bergentziako egiturek Hego Pirinioko zamalkadurarekin batera garatutako S-ranzko bergentziako egituren eragina pairatzen dutelako. Bestela esanda, zamalkadura-eredu bakun bat atzerako-zamalkadura elkartua duena ez da aplikagarria Pirinioan [7].

Zamalkadura nagusia bere atzerako-zamalkaduraren ondorengoa izatea nola litekeen azaltzeko, EHUko ikertzaileek falka tektoniko bakun bat proposatu zuten (2. irudia) [3]. Eredu horren arabera, falka tektonikoa Iberiako plakan barneratzean, Iberiako plakaren goi-lurrazala, hasiera batean, Nrantz baino ez zen zamalkatuko (Ipar Pirinioko zamalkadura), baina konbergentziak eragindako esfortzua behar bestekoa izan zenean Iberiako plakaren goi-lurrazal osoa zeharkatuko zuen zamalkadura nagusia sortuko zen (Hego Pirinioko zamalkadura). Horrela, esfortzuen berrantolaketa gertatzen da, eta aurretik Ipar Pirinioko zamalkadurarekin harremana zuten egiturek xurgatutako konbergentzia, ondoren, Hego Pirinioko zamalkadurarekin harremana duten egiturek xurgatuko dute. Geometria horrek ondo azaltzen ditu Pirinioko egitura kortikala, aurkako bergentziak eta egitura bakoitzaren adin-desberdintasuna.

Talka-fase horretan, beraz, bi fase tektoniko bereizten dira [1]: $\mathrm{N}$ ranzko bergentziako bat, lehenik, eta S-ranzko bergentziako beste bat, ondoren.

\subsection{N-ranzko bergentziako fase tektonikoa}

N-ranzko bergentziako konpresio-egiturek adierazten dute Bizkaiko golkoaren rifting-aldiaren ondorengo Iberia eta Eurasiaren arteko talkaren hasiera. Europar plakaren falka sartu egiten da Iberian, eta N-ranzko bergentziako egiturak sortzen ditu gaineko blokean (2. irudia). Egitura horiek Euskal Arkuan kokatutako arroko sedimentu sakonenen gainean dute eragina, gaur egun Bizkaia eta Gipuzkoa iparraldean eta Lapurditik ekialdera azaleratzen direnak. Ingurune horretan estentsioa nagusi zen bitartean arroaren hondoratzea eragin zuten faila normal ugari garatu ziren, eta konbergentzia hasi zenean egitura horiek izan ziren esfortzu berriei erantzuten lehenak. Horrela, faila normal askoren inbertsio tektoniko positiboa gertatu zen (alderantzizko faila gisa jokatzen dute esfortzu berrien aurrean), So- 
pelako Atxabiribil hondartzan argi gelditzen den moduan [8]. Era berean, konpresioaren eraginez, N-ranzko bergentzia nabarmena erakusten duten toles angeluar estuak (4. irudia) eta alderantzizko faila berriak garatzen dira. Egitura hauek ikusteko lekurik aproposena zalantzarik gabe Barrikako (Bizkaia) labarrak dira [9]. Deformazio handiko zonetan, foliazio tektoniko edo klibaje larri bat, $S_{N}$ (2. irudia), garatzen da, nabarmenagoa dena Albiarreko eta Goi Kretazeoko segida pelitikoetan.

Euskal Arkuko landa-behaketek agerian jartzen dutenez, N-ranzko bergentziako egiturak S-ranzko bergentziako ondorengo beste egitura batzuek deformatu dituzte, eta horrek aukera ematen du haien erlazio kronologiko erlatiboa zehazteko (5. irudia). Zaila da fase horien adina zehaztea, deformazioaren migrazioa gertatzen delako N- eta S-ko lurraldeaurre-zonetarantz; horretaz gainera, ez dago sinkroniarik egituren norabide paraleloan. Nolanahi dela ere, Bizkaiko golkoko ozeano-hondoaren berreraikuntzaren arabera, Iberia-Eurasia talka Campaniarrean datatu daiteke, orain dela 79 Ma inguru.
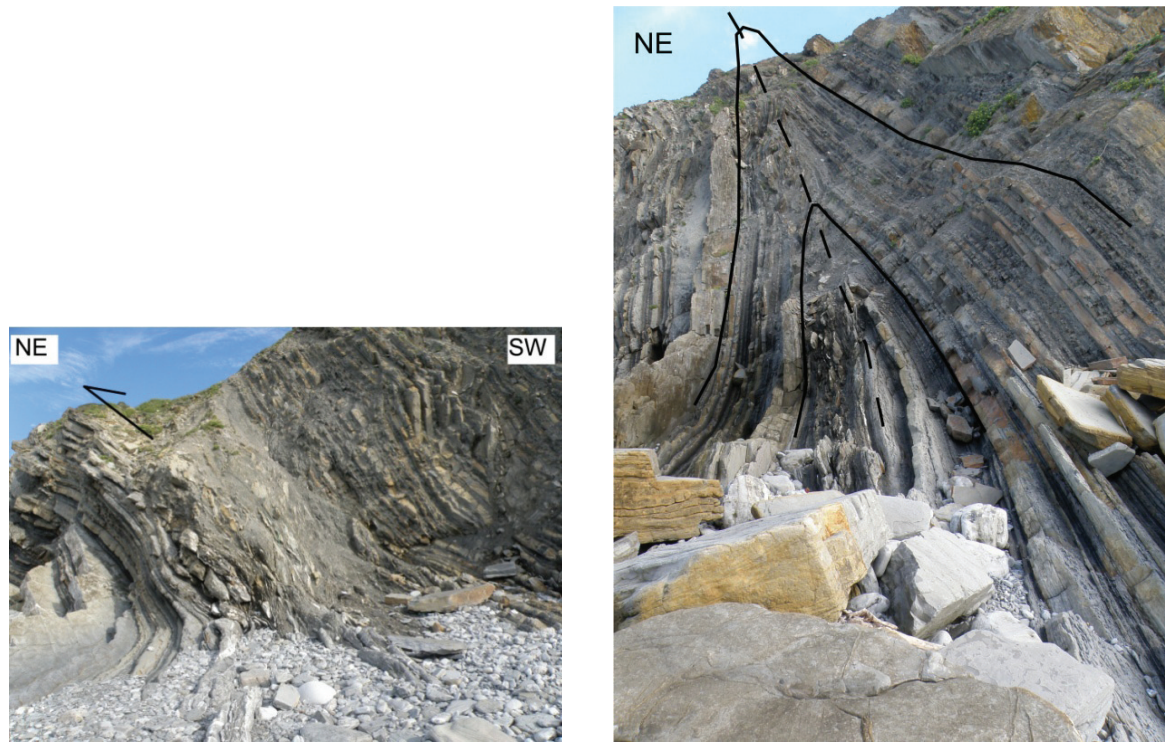

4. irudia. Barrikako labarretan agertzen diren egitura nagusiek (toles eta failak) N-NE-ranzko bergentzia erakusten dute, hain zuzen, konpresioaren lehenengo fasearekin (N-ranzko bergentziakoa) lotzen direnak ([8]-tik moldatua).

Aldi horretan, estalki sedimentarioaren laburtzea gutxienez $57 \mathrm{~km}$ izan zen Ipar Pirinioko zonan, eta gutxienez 4 km Euskal Arkuan [10]. Horregatik, fase horretarako kontuan hartzen den gutxieneko laburtzea $61 \mathrm{~km}$ da. 
2. irudian, Eurasiak Iberian sortu zuen indentazioaren geometria posible baten eskema ageri da.
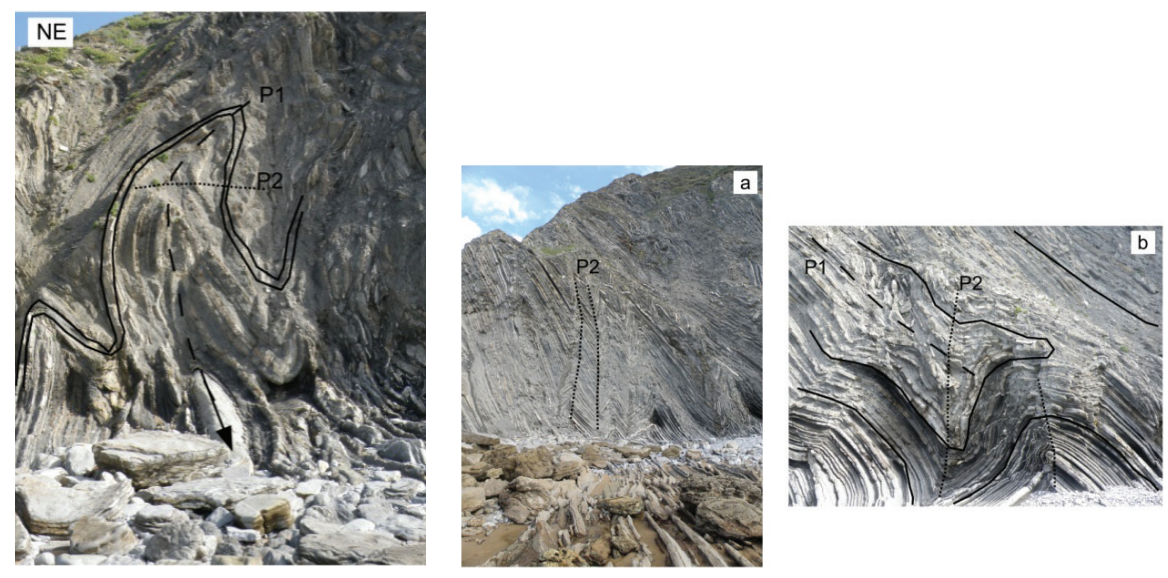

5. irudia. Barrikako labarretan agertzen diren tolesen interferentzia-egiturak. Nabarmena da nola S-ranzko bergentziako egiturek N-ranzko bergentziakoak birtolesten dituzten ([8]-tik moldatua).

\subsection{S-ranzko bergentziako fase tektonikoa}

Iberia eta Europaren arteko etengabeko konbergentziaren uneren batean, Europak duen falka geometriaren ondorioz, S-ranzko bergentzia duen Toloño mendilerroko zamalkadura garatzen da (1. eta 2. irudia). Aurrerantzean, Toloño mendilerroko zamalkadurak (6. irudia), zamalkadura nagusi gisa jokatuko du eta konbergentziaren gehiena xurgatuko du. Ondorioz, Ipar Pirinioko fronte-zamalkadura atzerako zamalkadura elkartu gisa birraktibatuko da. Azken geometria Iberia Eurasia azpitik subdukzitu izanaren eta Toloño mendilerroko eta Ipar Pirinioko fronte-zamalkaduren gaineko prisma delaminatu bat sortu izanaren ondorioa da. S-ranzko bergentziako egiturak Iberia-Eurasia talka-fasearen barnean ondo bereizitako bigarren urrats bati dagozkio. Fase horretarako kalkulatutako gutxieneko laburtzea $16 \mathrm{~km}$ da [11] (2. irudia).

Esfortzuen aldaketa horren argigarri dira N-ranzko bergentziako aurretiko egiturak deformatzen eta eraldatzen dituzten S-ranzko bergentziako egitura berriak. Adibidez, oso deigarriak dira Barrikako labarretan (Bizkaia) eta Leitzako failaren inguruan, $\mathrm{N}$-ranzko bergentziako toles angeluar estuak nola birtolestuta agertzen diren S-ranzko bergentziako eta eskala txikiagoko toles irekiagoen bitartez, interferentzia-tolesak sortuz (5. eta 7. irudiak). Bergentzia-aldaketaren beste froga bat da nola S-ranzko bergentzia izatera igarotzen diren, alderanzketa progresibo baten bitartez, in- 


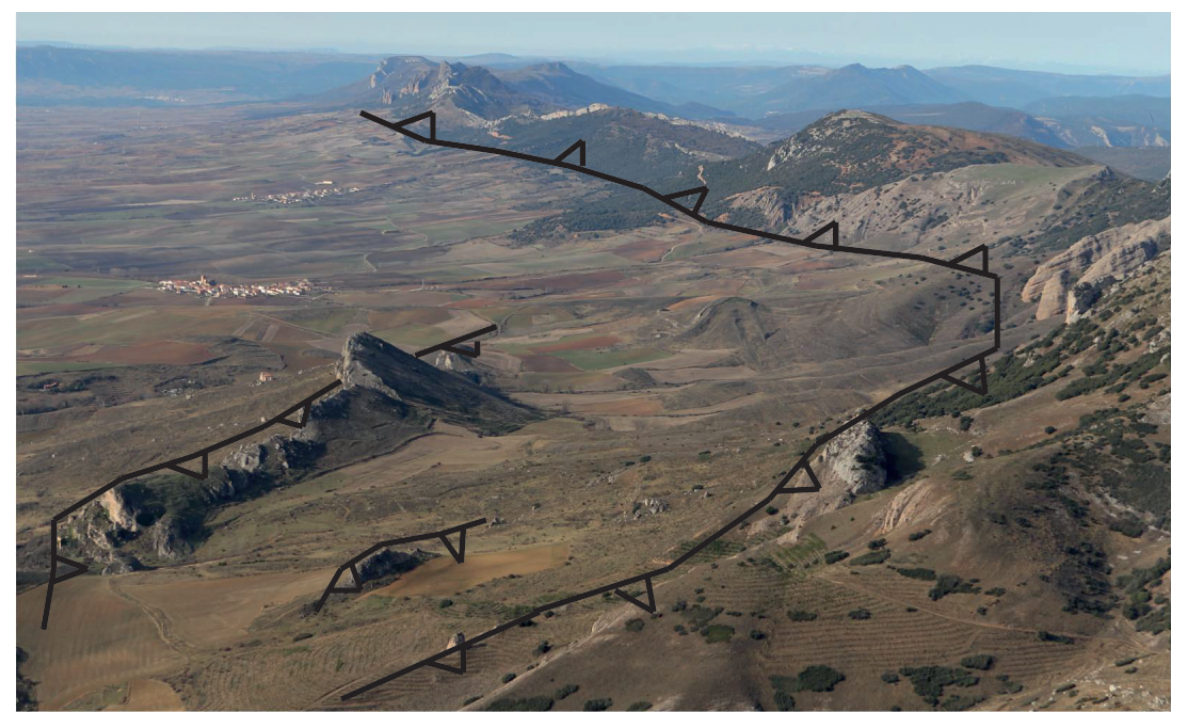

6. irudia. Toloño mendilerroko zamalkaduraren argazkia. Zamalkadurak Euskokantauriar arroa Ebroko arro gaztearen gainean kokarazten du. S-ranzko bergentziako fasea egitura nagusi hau sortzean abiatu zen.

guru berean ikusten den eta jatorriz N-ranzko bergentzia zuten tolesen ardatzak (5. irudia) edo zamalkadura-azalerak (8. irudia). Horretaz gainera, $\mathrm{S}_{\mathrm{s}}$ (2. irudia) foliazio tektonikoa garatzen da, egitura horren inguruetan tarteka ikusgai dena. Oro har, $\mathrm{S}_{\mathrm{s}}$ foliazio hori, litologiak oso baldintzatua badago ere, aurreko $S_{N}$ (2. irudia) foliazioa baino hedatuagoa da, eta okerdura txikiagoak ditu.

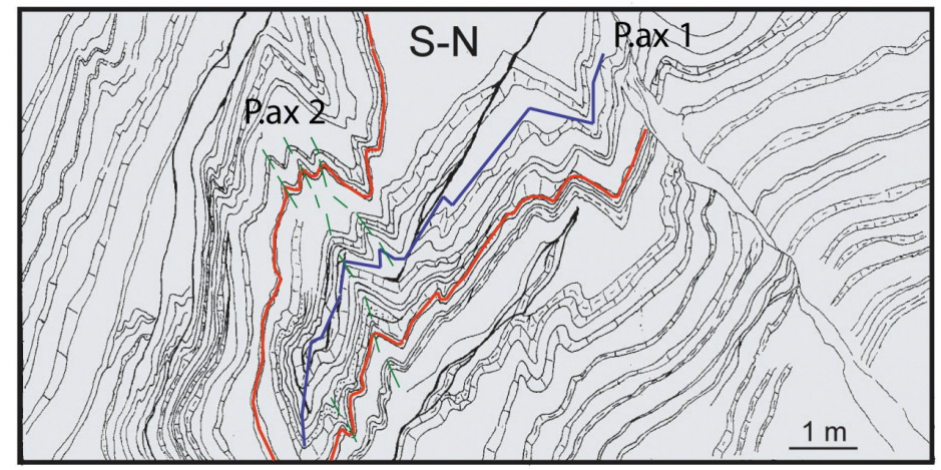

7. irudia. N-ranzko bergentziako tolesak (Pax 1, plano axialaren kokapena), S-ranzko bergentziako beste toles batzuek (Pax 2, plano axialak lerro etenak) tolestuak. N-I autobidea, Alegiatik hurbil ([1]-etik moldatua). 
Datu kartografikoek adierazten dute S-ranzko bergentziako fase horren hasiera Lutetiarraren ostekoa eta Oligozenoaren aurrekoa dela; beharbada, Priaboniarra (37 Ma). Une horretan sortuko ziren S-ranzko bergentziako egiturak. Toloño mendilerroko zamalkaduran ontzat ematen da adin Oligozeno bat, Miozenoan zehar berraktibatua [10]. Beraz, landa-datuetatik abiaturik, S-ranzko bergentziak duen iraupena Priaboniarrean hasi eta, gutxienez, Miozenoan luzatzen da.

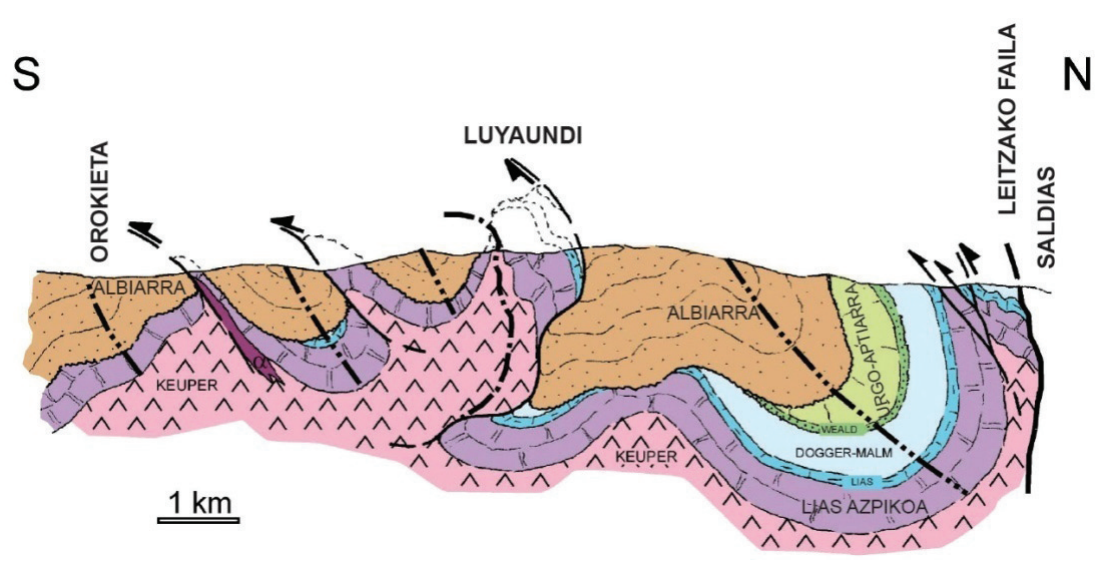

8. irudia. S-ranzko bergentziako toles eta zamalkadura berriak eta bergentziaren alderanzketa jasan duten jatorriz N-ranzko bergentziadun tolesak eta zamalkadurak erakusten dituen zehar-ebakia. Orokieta-Saldias errepidea ([1]-tik moldatua).

\subsection{Konpresio-etapak ikuspegi tektonosedimentariotik: kontinente-ertz aktiboa, hondar-arroa, lurraldeaurre-arroa eta mendi barneko arroak}

Plaken arteko konbergentzia hasten denetik sedimentazio-baldintzak aldatu egiten dira baina Euskokantauriar arroaren eboluzioak aurrera darrai. Fase horretan sortzen diren prozesu eta arro sedimentarioen arabera hainbat etapa bereiz daitezke: kontinente-ertz aktiboko etapa, hondar-arroa (foredeep), lurraldeaurre-arroa (foreland, zentzu hertsian) eta mendi barneko arroak (edo sakonune postorogenikoak) [12]. Estentsiozko erregimen batetik konpresio-erregimen batera pasatzean arroaren inbertsio tektonikoa gertatu zen. Inbertsio tektoniko horrek mendikatearen sorrera ekarri zuen, eta, beraz, ordura arte, batez ere uraren azpian metatutako materialen urgaineratzea. Etapa-segida hori Santoniar-Campaniarraren amaieratik Miozenora garatu zen (84-15 Ma, gutxi gorabehera), eta etapa horretan sortutako arroen arteko igarotzea nahiko progresiboa izan zen, bai denboran, bai espazioan. 
Kontinente-ertz aktiboaren etaparen hasiera esfortzu nagusien erregimen-aldaketarekin hasi zen, eta Santoniarraren amaieratik Eozenoaren hasiera bitartean iraun zuen (29 Ma inguru). Tarte honetako aldaketa sedimentario nagusia izan zen apurka-apurka arroaren ertzetako materialak uraren gainetik kokatzen hasi zirela - beraz higadurapean - eta bertan sortutako metakinak ziren arroa elikatzen zutenak. Horrela sortu zen etapa honetako fazies bereizgarrienetako bat, Orioko ildoan metatutako Flysch hareatsua.

Eozenoaren hasieratik aurrera konpresio-prozesua bizkortu egiten da, arroaren barneko zonak urgaineratu egiten dira (iparraldekoak), eta, hala, hondar-arroaren garapena hasten da, oro har (9. irudia). Etapa horretan, fazies bereizgarria metatzen da (flysch tektofaziesa), oso segida lodia eratuz arroko inguru sakonenetan (Euskal arkua), eraketa-prozesuan zeuden mendikateetako eremu urgaineratuen higaduratik zetozen metakinekin [12].

Goi Eozenoan eta Oligozenoan zehar, sedimentazio itsastarra oso eskasa da, ingurune zehatzetara mugatua, eta arroaren hegoaldeko ertzean izaera guztiz kontinentala du sedimentazioak. Aldaketa progresibo honek markatzen du hondar-arroaren eta lurraldeaurre-arroaren arteko trantsizioa.

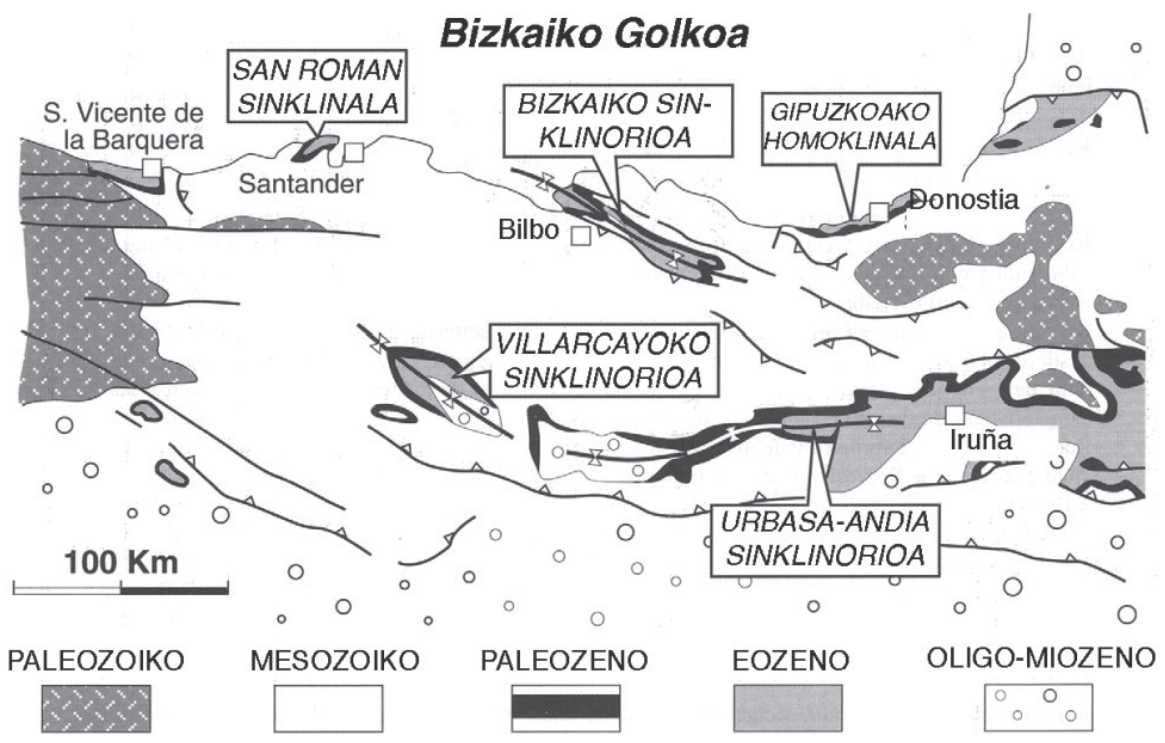

9. irudia. Euskokantauriar arroko Paleogenoko azaleramenduen mapa ([12]-tik moldatua).

Azkenik, Miozenoan, mendi barneko arroak eratu ziren orogenoko eremu deformatuaren barruan. Mendi barneko arroek edo sakonune pos- 
torogenikoek izaera kontinentala dute, eta tamaina txikia (aurretik sortutakoen aldean); orogeno baten barruan garatzen dira haren deformazioprozesuaren amaieran, eta, neurri handi batean, inguruko goraguneetan higatutako materialez elikatzen dira. Arroaren bilakaera tektonoestratigrafikoaren azken etapa osatzen dute; haien garapena pixkanaka gertatu zen, nagusiki Miozenoan, segur aski hegoalderanzko bergentzia duen fase tektonikoa berraktibatu izanarekin erlazionatuta (Toloñoko mendilerroaren zamalkaduraren berraktibatzea). Euskokantauriar arroaren hegoaldeko ertzean, mendi barneko bi arro bereizi ziren, Villarcayo-ko sakonunea eta Miranda-Trebiñuko sakonunea, biak ala biak Villarcayo-Trebiñu sinklinorioan kokatuak (9. irudia). Metatutako material zaharrenak - soil-soilik kontinentalak (zingiratarrak eta alubialak) - Miozenokotzat jo dira. Oligozenoko materialak, horiek ere kontinentalak, diskordantzia angeluarrez edo diskonformitatez daude Miozenoko materialen azpian; beraz, kate barneko sakonuneen genesiaren aurreko fase batekotzat jo behar dira (10. irudia).

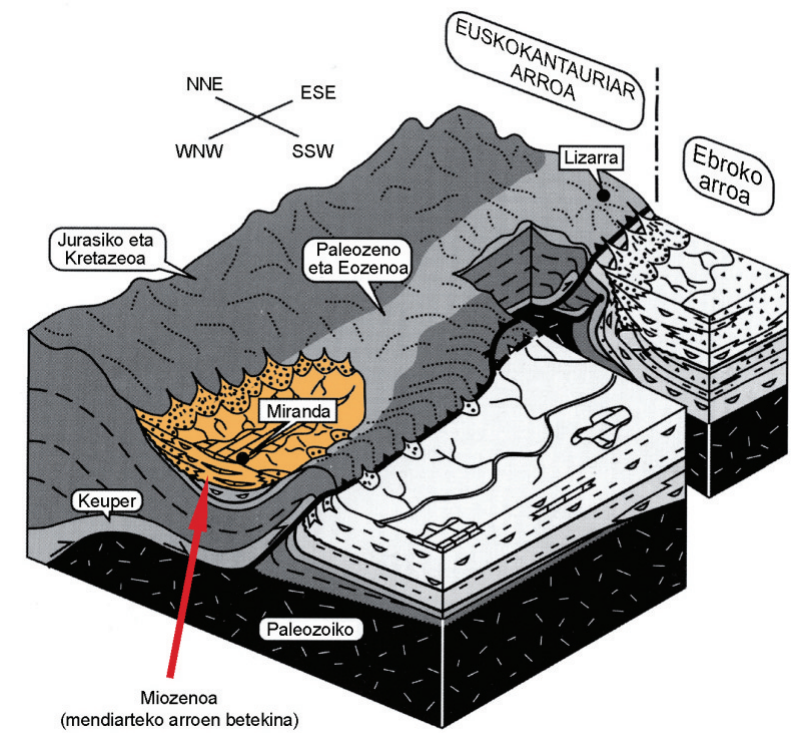

10. irudia. Miranda etaVillarcayoko mendi barneko arroen berreraikuntza (Miozenoa) ([12]-tik moldatua).

\section{ESKER ONAK}

Egileok eskertu nahi dugu Luis Miguel Martínez-Torresek eta Sergio Roblesek erakutsitako prestutasuna Euskokantauriar arroari buruz dakitena gurekin partekatzeko. 


\section{BIBLIOGRAFIA}

[1] MARTÍNEZ-TORRES, L.M. eta EGUÍLUZ, L. (2014)«®Dinamika kortikala eta pultsu termotektoniko alpetarrak Euskokantauriar arroan eta mendebaldeko Pirinioan». Non: BODEGO, A., MENDIA, M., ARANBURU, A. eta APRAIZ, A. (edk.). Euskokantauriar arroko eboluzio geologikoa. Euskal Herriko Unibertsitateko Argitalpen Zerbitzua, Bilbo, 105-118.

[2] MARTÍNEZ-TORRES, L.M. (1991). «El Manto de los Mármoles (Pirineo Occidental): geología estructural y evolución geodinámica». Tesi doktorala, Euskal Herriko Unibertsitateko Argitalpen Zerbitzua, Bilbo, 294 or.

[3] MARTÍNEZ-TORRES, L.M.,RAMÓN-LLUCH, R. eta EGUÍLUZ, L. (1994). «Tectonic wedges: geometry and kinematic interpretation». Journal of Structural Geology 16, 1491-1494.

[4] ECORS-PYRENEES PERFIL TEAM (1988). «The ECORS deep seismic survey across the Pyrenees». Nature 331, 508-511.

[5] MUÑOZ, J.A. (1992). «Evolution of a continental collision belt: ECORSPyrenees crustal balanced cross-section». Non: McCLAY, K.R. (ed.). Thrust Tectonics. Chapman and Hall, New York, 235-246.

[6] PULGAR, J., GALLART, J., FERNÁNDEZ-VIEJO, G., PÉREZ-ESTAÚN, A., ÁLVAREZ-MARRÓN, J. eta ESCIN Group (1996). «Seismic image of the Cantabrian Mountains in the western extension of the Pyrenees from integrated ESCIN reflection and refraction data». Tectonophysics 246, 1-19.

[7] MARTÍNEZ-TORRES, L.M.,RAMÓN-LLUCH, R. eta EGUÍLUZ, L. (1994). «Tectonic wedges: geometry and kinematic interpretation». Journal of Structural Geology 16, 1491-1494.

[8] VISSERS, R.L.M. eta MEIJER, P.Th. (2012). «Iberian plate kinematics and Alpine collision in the Pyrenees». Earth-Science Reviews 114, 61-83.

[9] APRAIZ, A. (2014). «Tolesen eta failen ikuskizuna: Barrika, flyschak dardar egiten duen tokia». Non: BODEGO, A., MENDIA, M., ARANBURU, A. eta APRAIZ, A. (edk.). Landa Geologia: 12 irteera euskokantauriar arroan zehar. Euskal Herriko Unibertsitateko Argitalpen Zerbitzua, Bilbo, 103-120.

[10] MARTÍNEZ-TORRES, L.M. (1997). «Transversal a la Cuenca Vasco-Cantábrica. Introducción a la estructura y evolución geodinámica». Euskal Herriko Unibertsitateko Argitalpen Zerbitzua, Bilbo, 121 or.

[11] MARTÍNEZ-TORRES, L.M. (1993b). «Corte balanceado de la Sierra Cantabria (Cabalgamiento de la Cuenca Vasco-Cantábricasobre la Cuenca terciaria de Ebro)». Geogaceta 14, 113-115.

[12] ROBLES, S. (2014). «Euskokantauriar arroko eboluzio geologikoa». Non: BODEGO, A., MENDIA, M., ARANBURU, A. eta APRAIZ, A. (edk). Euskokantauriar arroko geologia. Euskal Herriko Unibertsitateko Argitalpen Zerbitzua, Bilbo, 9-104. 